\title{
Euthanasia debate reignited
}

Previously published at www.cmaj.ca

$\mathrm{F}$ ew health care topics stir debate like euthanasia and assisted suicide, and some right-to-die advocates believe that debate is slowly, but inexorably, shifting in their favour.

Although assisted suicide recently became legal in a second American state and increasing numbers of people are seeking aid in dying at European clinics, the issue has essentially lain dormant in Canada since Liberal Senator Sharon Carstairs' unsuccessful efforts of roughly a decade ago to introduce legislation shielding health care providers from criminal liability if they honoured patients' wishes to withhold or withdraw life-sustaining treatments.

Yet, that may be about to change as a Quebec College of Physicians task force on ethics weighs in this November with a discussion paper containing specific recommendations on physicianassisted suicide. Meanwhile, Parliament is expected to debate a private member's euthanasia bill this fall (although the bill will die on the order paper if a federal election is called).

Momentum for legislative change may be gathering because populations in most parts of the world are rapidly aging, suggests Ruth von Fuchs, president and secretary of the Right to Die Society of Canada.

"I think more people have seen someone die badly, someone close to them, and they think there has to be a better way," says von Fuchs, adding that euthanasia should be part of "the continuum of care, the ultimate palliation. Sometimes the most appropriate way to deal with suffering is to take away the substrata; life is what allows suffering to occur."

That's been the case in Oregon since 1997, when the state enacted its Death with Dignity Act, which "allows terminally-ill Oregonians to end their lives through the voluntary self-administration of lethal medications, expressly pre-

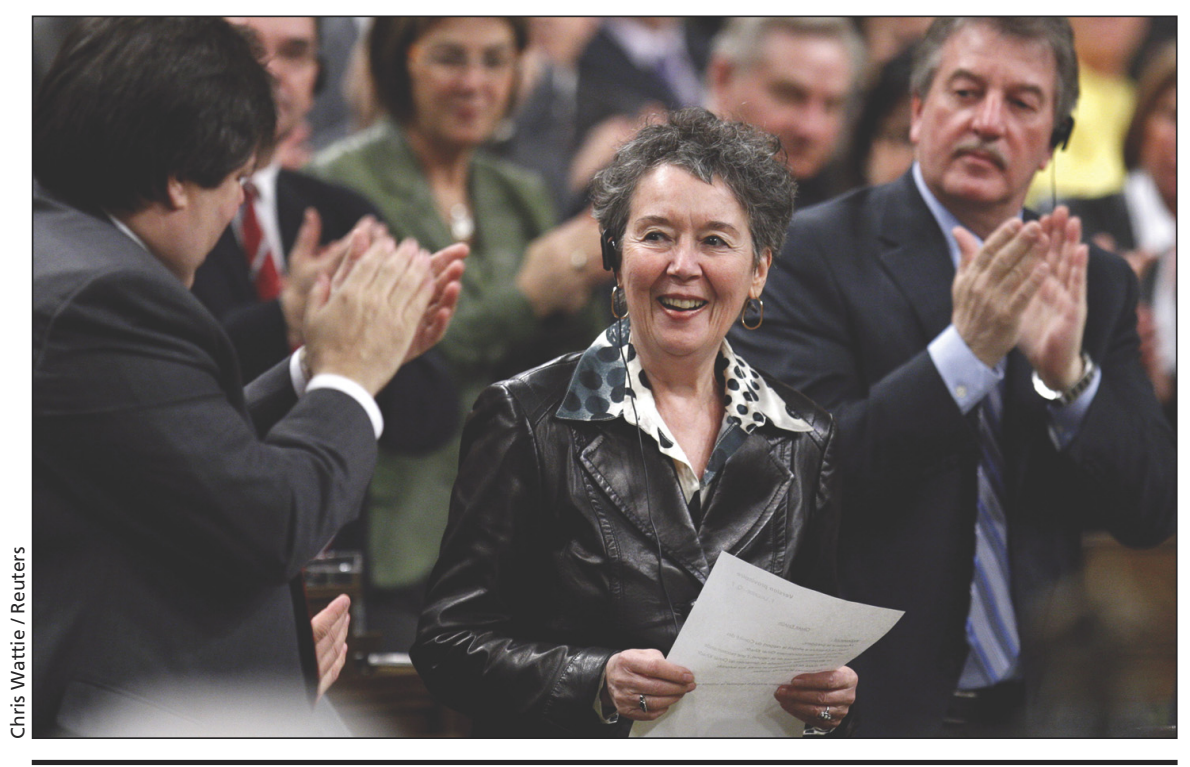

"The time has come for this Parliament to find a way to decriminalize medical assistance in dying, which is of such vital importance to those whose suffering can no longer be relieved except by this ultimate compassion," Francine Lalonde, Bloc Québécois Member of Parliament (La Pointe-de-l'Île) said while introducing Bill C-384.

scribed by a physician for that purpose." In May, a woman suffering from pancreatic cancer became the first person to die under the protection of similar legislation in Washington, which last year became the second state to legalize physicianassisted suicide.

In the Netherlands, physicianassisted suicide has been legal since 1993 and enjoys widespread public support. It is now also legal in Switzerland, where more than 100 British people have journeyed to end their lives, including the conductor Edward Downes, who, though not terminally ill, chose to die alongside his cancerstricken wife in July at the Dignitas clinic in Zurich.

Canadian physicians have traditionally been hesitant to enter this public and at times heated debate, but the Quebec College of Physicians task force on ethics, which has been privately debating the issue for several years, proposed that euthanasia be included "as part of the appropriate care in certain particular circumstances."

The task force, which does not sup- port assisted-suicide clinics, is expected to release its specific recommendations in November in an effort to pressure the federal government to change the Criminal Code to legalize euthanasia. This is necessary, according to the College, because terminally ill patients sometimes suffer from pain so intense that the dose of painkillers required to control it can be fatal; therefore, in effect, euthanasia is already commonplace and the law should be changed to reflect that.

That argument, however, is seen by some opponents of euthanasia as not only weak but nonsensical. Causing deaths through efforts to reduce pain, they argue, is very different than administering overdoses with the intent to end lives.

"Pain relief treatment is not euthanasia and giving increasing doses of narcotics can be incompetent medical practice - at a certain point different pain relief modalities can be required. Unfortunately, some physicians' medical knowledge is substandard in this regard," Margaret Somerville, director 
of the Centre for Medicine, Ethics and Law at McGill University and author of Death Talk: The case against euthanasia and physician-assisted suicide, writes in an email to CMAJ.

Alex Schadenberg, executive director of the Euthanasia Prevention Coalition, likewise argues that the rationale offered to support the Quebec College of Physicians' proposal is lacking. Providing comfort has nothing to do with intentionally ending a life, he says, and physicians are not charged for improper use of opioids if a patient dies as a result of accepted pain-relief practices.

"If we were to go down the route they are talking about, it would create more confusion," says Schadenberg, who believes, if the College's proposal became law, doctors would be under more scrutiny when patients on pain medication die. "Why did they use that high amount? Did they use it to kill the pain or kill the patient?"

Also expected to drive the euthanasia agenda this fall is Bill C-384, a private member's bill introduced by Francine Lalonde, that seeks amendments to the Criminal Code to permit the "right to die with dignity." The bill survived first reading and is expected to be debated in the House of Commons unless Parliament is dissolved as a result of a nonconfidence vote in the minority government.

The bill states that medical practitioners would not be considered to be committing homicide when they assist in the deaths of people who are at least 18 years old, have severe "physical or mental pain without prospect of relief" and have "provided a medical practitioner, while appearing to be lucid, with two written requests more than 10 days apart expressly stating the person's free and informed consent to opt to die."

Schadenberg forecasts that, as with two previous attempts to legalize euthanasia, the bill will fail, in part because its language is too broad. He also takes particular issue with the phrase "appearing to be lucid." That is quite different, he says, from actually being lucid, which in itself can be difficult to assess. - Roger Collier, CMAJ

DOI:10.1503/cmaj.109-3034

\section{Regulatory colleges to set painkiller guidelines}

Previously published at www.cmaj.ca

$\mathrm{F}$ aced with staggering increases in opioid prescribing, rising rates of addiction and criminal activity, as well as an apparent vacuum in national leadership, provincial colleges of physicians and surgeons are banding together to craft opioid use guidelines.

Draft guidelines have been circulated to a national advisory group of experts in a bid to achieve consensus and are expected to be finalized in October as part of the provincial colleges' unprecedented move to create national clinical practice guidelines.

Canadian doctors prescribe almost twice as many of the powerful and addictive painkillers as they did a decade ago, making Canadians among the world's top consumers of prescription opioids.

While that likely means better pain control for select groups - such as cancer and palliative care patients - the colleges are concerned that physicians are inappropriately prescribing opioids for all manner of ailments. Others suggest that the colleges also hope to obviate rising concern about physician liability.

Janet Wright, assistant registrar of the Colleges of Physicians and Surgeons of Alberta, says the regulatory colleges decided to step in because no one had created national guidelines. "It is really unusual for regulatory bodies to produce guidelines and we had lots of discussion about whether we should. ... But there was a void."

Wright adds that the colleges also felt compelled to act because doctors have identified opioid prescribing as a "tough practice area." A survey con-

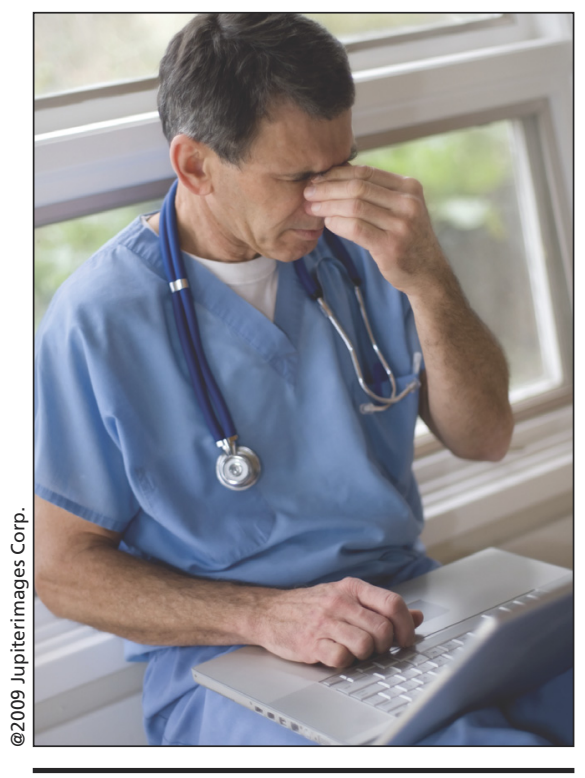

Surveys indicate that one of the most puzzling challenges that doctors face is appropriate use of opioids for chronic pain management. ducted by the College of Physicians and Surgeons of Ontario found that family physicians ranked chronic pain management second only to mental health as a challenging area of clinical practice.

In British Columbia, "we found out that most doctors don't really know the rules of the road when prescribing for someone with chronic noncancer pain," says Dr. Robert Vroom, deputy registrar for the College of Physicians and Surgeons of BC. "Why should we be punishing our doctors for something they don't know? This is one of those big gaps in their education and we thought we should do something to help doctors rather than beat them up."

The draft clinical practical guidelines now being circulated were created by an academic group at the Institute for Work and Health in Toronto, Ontario, that had earlier developed a chapter on opioids for the Ontario college's guidelines on chronic noncancer pain, says Dr. Andrea Furlan, evidence-based practice coordinator for the Institute. It's expected the guidelines will eventually be maintained, and regularly updated, by the new Michael G. DeGroote National Pain Centre being established at McMaster University in Hamilton, Ontario.

Wright says the colleges jointly funded the National Opioid Use Guide- 